\title{
COMPUTER AIDED TRANSLATION - POSSIBILITIES, LIMITATIONS AND CHANGES IN THE FIELD OF PROFESSIONAL TRANSLATION
}

\author{
PATRYCJA KARPIŃSKA \\ Institute of English Studies, University of Wrocław, \\ Kuźnicza 22, Wrocław, Poland \\ E-mail address: patrycja.karpinska@uwr.edu.pl
}

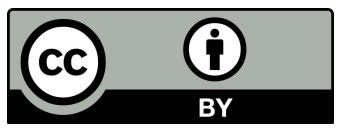

\begin{abstract}
The aim of this article is to investigate the usefulness and applicability of CAT (Computer-Aided Translation) programs in relation to the qualities (e.g. standardisation, predictability, terminology) of the translated text. In the study, both scientific articles and translator's forums are taken into account in order to establish advantages and limitations of commercial CATs. It appears that CAT programs influence cognitively the translator's work and even though they are supposed to facilitate his or her work, they may hinder or slow down the process of translation. These programs are also applicable only in the case of certain types of texts, namely those which are standard and predictable and they fail in the case of texts which are linguistically or culturallycoloured. Furthermore, translators express numerous practical concerns regarding CATs (e.g. their price, instability). However, their use has become a very basic translation skill and it is no longer an advantage but an absolute necessity for anyone wishing to work as a translator..
\end{abstract}

Key words: Computer-Aided Translation, machine translation, equivalence, literary translation

\section{INTRODUCTION}

Personal computers and the Internet have become internal elements of everyday life in the 21st century. This technological revolution, which affects various spheres of everyday life (e.g. both private and professional), has resulted in the complete make-over of certain professions and in the drastic changes in numerous professional practices. Translators could be an example of a professional group that has gone through such a radical transition.

The first tools exploiting the process of translation already appeared in the first half of the 20th century, when the personal computer was not discussed much in the public sphere and Alan Turing's Colossus was one of the major technological achievements. The real technological revolution took place in the 80s, when linguists attempted the writing the first programs for automatic text translation. Even though they failed and the initial automa- 
tic translations constitute fascinating curiosities rather than real working tools, these attempts opened the path for CAT programs (Computer-Aided Translation). CAT are a group of complex programs combining numerous and varied functions that all have the same aim - to make the translator's work more efficient. For quite a long time, CAT tools were dedicated to work which did not require Internet access. At first, they functioned as personalised programs which could be used on one device only; then, they were designed as server tools, which allowed for communication e.g. within the office, but generated additional costs. Furthermore, the interface was quite complicated and required some basic programming knowledge. The so-called WYSIWYG trend (namely, What You See Is What You Get) only recently has been introduced to CAT. CAT programs themselves have become more popular and widely used by translators only in the 21st century (Folaron 2010, pp. 429-432; Choudhury, \& McConnell, 2013, p. 16).

In the present article, the author presents the basic computer tools applied in the translator's work with an emphasis placed on CAT programs, their possibilities and restrictions. However, in the discussion on the computer-aided translation, one should also mention the social changes which have been brought by the technological development as well as the dangers to the translator's profession and remedies thereto.

\section{BASIC TOOLS IN THE TRANSLATOR'S WORK AND THEIR POSSIBILITIES}

Perhaps, this quite practical overview of tools dedicated to translators should begin with their theoretical classification. In the literature, there is a scale on which translation tools are classified. On its one end, there is Machine Translation (MT), comprising all programs that translate the text automatically without any human intervention. On the other end, there is Human Translation (HT), comprising the translation performed by humans without any technological support. However, it should be highlighted that both ends of the scale are virtually unreachable. Between these ends, two other categories are distinguished - HAMT (Human-Aided Machine Translation), which is automatic translation supported by a human, ${ }^{1}$ and MAHT (Machine-Aided Human Translation), i.e. the programs that aim at supporting the translation process and that are supposed to supply the translation with necessary tools, yet that are still based mostly on human work. CAT programs belong to the last category; these are not only the most developed and common tools on the translation market but also the most specialised ones, created exclusively for translators (Bowker, 2002, p. 7; Folaron, 2010, pp. 432-433).

Two of the most significant functions of CATs are Translation Memory (TM) and Term Base (TB). These are very characteristic of CAT and they appear rarely in any other type of programs. Translation memory is a file saved in the format

1 For instance, crowd-sourcing. 
characteristic of a given CAT program (e.g. * .sdlxliff for SDL Trados and *.mqxliff for MemoQ); it contains already translated pairs of the source and the target texts. The program automatically searches all loaded translation memories and signals whether there is any similarity between the new text and the older already translated segments, which can be further used by a translator in his or her work. Depending on the settings and the translator's preferences, the program can display the translation segments which are identical with the present text (i.e. exact match translation memory) as well as an ability to look for similar segments (i.e. fuzzy match translation memory), as well. The translator can decide on the level of similarity that interests him or her, e.g. he or she can decide that the program should signal solely segments which are similar to the present text to $80 \%$ or higher. ${ }^{2}$ Clearly, translation memory is a useful function only if one already has a package of TMs dealing with similar issues and topics as the non-translated text does. However, the translator does not need to rely on his or her own work; various translation memories coming from different sources can be loaded into the program, e.g. those sent by the employer or project manager (Choudhury, \& McConnell, 2013, pp. 20-21). The European Union creates official packages of translation memories, which can be downloaded without any additional fees from the official EU websites and applied in the translation of legal or economic documents. ${ }^{3}$ Translation memory is also used by MemoQ, one of the most popular CAT programs, in the so-called Muse. Owing to Muse, as time passes and translators upload more and more texts, the program 'learns' translators' writing styles and offers itself ready phrases and sentence constructions, which can be copied to the target text with one hot key.Term bases are collections of words and phrases paired with their translation; a translator can create one from the scratch or upload and edit already existing ones. This function is particularly applicable in the translation of a text characterized by the accumulation of terminology, keywords, proper nouns, etc. If the term base is properly prepared, all terms can be introduced into the target text with one hot key. Furthermore, glossaries also offer the creation of so-called "blacklists," i.e. the words and phrases that should not be translated. In such case, phrases from the source text are automatically transferred to the target text (Choudhury, \& McConnell, 2013, p. 20).

Term bases are collections of words and phrases paired with their translation; a translator can create one from the scratch or upload and edit already existing ones. This function is particularly applicable in the translation of a text characterized by the accumulation of terminology, keywords, proper nouns, etc. If the term base is properly prepared, all terms can be introduced into the target text with one hot key. Furthermore, glossaries also offer the creation of so-called "blacklists," i.e. the words and phrases that should not be translated. In such case, phrases from the source text are automatically transferred to the target text (Choudhury, \& McConnell, 2013, p. 20).

2 Sentence similarities are calculated on the basis of e.g. the VSM-based algorithms (vector space model), word- and syntax-based algorithms or Levenshtein distance algorithm (Wei, 2013, p. 198).

3 EU Science Hub Website, The European Commission's science and knowledge service. 
Today, CAT programs have numerous and varied functions which are sometimes not related to the process of translation per se but are supposed to make the program more attractive on the market. ${ }^{4}$ Some of these functions are worth mentioning to illustrate how developed and, in a certain sense, intelligent CAT programs are. For instance, a program can warn a translator once it finds in the translation memory pairs similar to the text in translation and discovers that the saved text and the current one are different. SDL Trados, another popular CAT, can signal places that may be potentially difficult in translation (or more difficult than the rest), e.g. due to the faux amis. ${ }^{5}$ Both SDL Trados and MemoQ control the compatibility of numbers between the two texts and the correctness of punctuation; they can also copy any string of numbers. Furthermore, they allow a translator to work on files with different formats, even if a translator does not have any other program to open these files and they work perfectly on pdf files. CAT programs have inbuilt grammarand spell-checkers; however, they offer the translator a choice between their checkers and those inbuilt in other text editors installed on the computer, e.g. Word Office or Open Office (Choudhury, \& McConnell, 2013, p. 23). Another useful function is concordance, which allows a quick search of a given term in the context in both translation memory and translated text. Even though CATs usually do not have an inbuilt machine translation, they can be connected to another program that allows translation of the text automatically in real time; most commonly, they connect with the one created and run by Google. Finally, MemoQ offers a function called X-Translate, which allows the merging of earlier files and their translations with the later versions. This function is particularly useful as it may quite often happen that a translator will receive the first version of the text from a client and then, after a couple of days, when the translator has already translated e.g. $70 \%$ of the text, the client would send the second version with slight changes (MemoQ website).

Other tools that support an audio-visual translator or interpreter are also worth mentioning. For instance, there are programs such as Viki or dotSub that allow a quick transcription of the audio, automatically create subtitles in the source language, count characters and syllables, or offer an advanced edition of the subtitles, e.g. by adding different colours and fonts. ${ }^{6}$ The tools supporting interpretation also evolve. In the modern world, a translator does not necessarily need to be physically present at a conference or meeting; he or she can easily interpret from home. There are also systems which allow the translation of a phone call and the interpretation is not performed con-

4 For instance, MemoQ offers ZEN. After we click on the proper button, the relaxation music starts to play. Funny as it may be, anyone who tried to translate a text at least once knows how frustrating this task can be and the relaxation music appears to be a nice touch from the creators of the program.

5 Faux amis, or false friends, are words which are very similar in form but different in meaning in two different languages, e.g. English "actually" and Polish "aktualnie" (which means "right now") or English "pretend" and Spanish "pretender" (which means "to try").

6 They are particularly used in the creation of subtitles for the disabled, e.g. the deaf. A given colour of the subtitle is assigned to the specific character in the film or TV series. 
secutively (when the speaker speaks and then the translator translates) but simultaneously, when the interpreter translates at the same time as the speaker speaks. The product of such interpretation resembles a phone voice-over (Choudhury, \& McConnell, 2013, p. 28).

\section{LIMITATIONS OF CAT PROGRAMS}

The above description could suggest that CAT programs are marvellous tools that facilitate a translator's work; yet, it is not always the case. Firstly, their possibilities are truly used only in the translation of texts characterized by high standardization (e.g. user's manuals, legal regulations, patents), which are terminological and predictable. Otherwise, the application of CAT programs might even obstruct the process of translation.

Anthony Pym claims that translation programs destroy text linearity. One usually works on texts which have a beginning, middle, end and a horizontal structure. Translation programs enforce a vertical order, which is non-intuitive. Not only all suggestions and translation memory results appear vertically but also the text loses its primary form and becomes a vertical stack of single, decontextualised sentences. In effect, a translator processes the information slower than usual - when the information is provided in a horizontal structure (Pym, 2011, p. 2). In spite of appearances, not only the structure of the information but also the number of options might slow down the translator's work - the effectiveness of translator's work drops when the translator is provided with long lists of synonymous words in the target language and lists of similar or suggested translations. A translator ceases to rely on his or her own intuition and trusts the choices of a machine, which might affect the naturalness and fluency of a target text (Pym, 2011, p. 2).

Furthermore, the division of the text itself is remarkably problematic. The programs automatically divide the text into sentences; however, it is worth asking whether such division of a text is the most beneficial for a translator. The issue of a translational unit - i.e. the optimal unit of a text on which a translator works and onto which a text should be divided in the process in translation so that the most structural links would be preserved - has not been resolved so far. Some theorists claim that a text is cognitively divided by a translator into units independent of the sentence and smaller than sentence units; others argue that a text is cognitively divided on the sentence level or into the units larger than a sentence (Munday, 2004, pp. 66-69). Apart from the issue of the translational unit itself, there is no doubt that working on the CAT programs, a translator moves cognitively toward translating each separate segment and as a result, he or she has less control and it is more difficult for him or her to preserve semantic and structural links between the sentences (Pym, 2011, p. 3). Moreover, this procedure also leads to the decontextualisation of the whole text - if a translator works solely with a machine, it is easier to forget about the vast social 
and cultural context, which the source and the target texts are written in (Pym, 2011, p. 6).

The limitations of CAT programs could be also investigated from the perspective of classic translation theories, e.g. the theory of equivalence. The term "equivalence" is quite ambiguous and different theorists use it in different senses. Olgierd Wojtasiewicz asserts that the essence of equivalence is to evoke the same or similar feelings in the readers of both source and target text readers (Wojtasiewicz, 2007, pp. 23-25). Clearly, one cannot expect that two different persons would feel exactly the same even if reading the same text and not the original and its translation. The author explains his idea of equivalence with the use of a metaphor. All people possess similar physiology - we have leucocytes but their level is different in different people; we have weight but our weight changes even daily. There is no such moment in the life of a given organism when it would be in exactly the same physiological state as it was before - yet, for most of our lives, we feel similarly. $O$. Wojtasiewicz claims that texts work on a comparable basis. Various readers read the text differently - even the same person reading the same text in a different moment of his or her life might understand it dissimilarly; the key is the said similarity.

O. Wojtasiewicz is not the only Polish scholar dealing with the issue of equivalence. Krzysztof Hejwowski defines equivalence as not similarity of feelings but similarity of text interpretations. K. Hejwowski also notices that when we discuss equivalence, we commonly do not consider the text itself but the applied translation techniques. In such a case, an equivalent text is the one in which most favourable translation techniques for a given context are applied (2007, p. 58).

Owing to the problematic nature of equivalence, there are numerous and varied theories developing the said issue. Perhaps the most popular (and the oldest) is the one proposed by Eugene A. Nida. E. A. Nida distinguishes two types of equivalence: formal and dynamic. Formal equivalence states that both source and target texts should have as similar form as possible, hence present similar syntactic structures, text layout, etc. The target text should appear as foreign to the reader, on both formal and cultural level. Dynamic equivalence focuses not on the form of the text but on the relation between the text and the source target reader and assumes that the said relation should be recreated between the target text and the target text reader. In this case, a translator is expected to have empathy as well as cultural and linguistic sensibility. The text should sound naturally in the target language and its readers should stay within their comfort zone and the sphere of their culture (Kielar, 1988, pp. 62-63).

Surely, it is not possible to always apply only formal or dynamic equivalence. At some points, a translation requires movement towards formal equivalence, whereas in others move towards dynamic equivalence. Depending on the type of the translated text, either formal equivalence may be prevalent (e.g. in technical texts) or dynamic (e.g. literary texts). Relating Nida's theory 
of equivalence to CAT programs, it is worth highlighting that CAT programs are not applicable once the dynamic equivalence is required as they do not display any sense of empathy, knowledge of the source and target culture as well as certain linguistic and cultural sensibility. CATs work best if one needs to apply formal equivalence, which in its basic form and assumptions is reminiscent of automatic translation. To conclude, CAT programs are useful in the translation of e.g. technical texts, whereas they might hinder the translator's work in the translation of literary text as they suggest (often unwanted and unnecessary) solutions typical of formal equivalence.

Finally, it is worth looking on CAT programs and their cons from more practical point of view. A. Pym argues that the use of CATs leads to the decline of translational standards, which already are a difficult and ambiguous issue (2011, p. 6). This argument appears valid, especially if a client - trying to save some money - instructs a translator not to check the text automatically translated by CAT programs or when it is an everyday practice to use automatic translations which eventually correct the automatically obtained text later on. What is more, CAT programs are quite complicated and difficult in use and several months of courses are often required so that a translator would be able to effectively use them in his or her work. For instance, in some CAT programs, one needs to know that each and every translation segment needs to be confirmed with a specific hot key. The program does not warn the user had he or she forgotten to confirm some of the segments - and the unconfirmed segments do not appear in the generated target text, which means that if one forgets to confirm all segments, the translation is incomplete. Moreover, CAT programs are usually based on Java technology, which is very unstable. Due to this issue, CAT programs easily crash, especially on bigger files; they are not working fluently; and a translator might easily lose his or her translation had he forgotten to save it every couple of minutes (Choudhury, \& McConnell, 2013, p. 17). There are no standard format files for translation memory or term base and the existing programs are not compatible with each other. Finally, the extremely high prices of CAT programs should be mentioned. For instance, the newest/latest version of SDL Trados Studio for translation office costs around 2,500\$ for each copy, which is a lot considering low translator's incomes (SDL Website).

\section{CHANGES AND DANGERS TO THE TRANSLATION PROFESSION}

Rapid technological development and the introduction of CAT programs on a large scale have led to significant changes in the translation profession. Above all, a translator more and more often does not work alone but in a team. From TAUS report, it emerges that the Simship model is becoming more and more popular on the translational market, which means that translations are not introduced on one market at a time as it was before, but on 
multiple markets simultaneously. In the 80s, the same text was introduced on 10 markets; in the 90s, on 25 markets; whereas now it is nearly 40 markets (Choudhury, \& McConnell, 2013, p. 14). CAT tools allow also an effective work in the numerous, sometimes international teams. All team members can see how far has the work gone on a given text, what changes are introduced and the whole process is coordinated by one person, e.g. a project manager (Folaron, 2010, p. 430).

However, apart from CAT tools, which are specialized programs requiring specific skills and education, every person who has access to the Internet, also possesses access to automatic translators, such as Google Translate. In effect, there are more and more quasi-translators on the market, i.e. persons who do not translate themselves but use available Internet translators and edit the machine translations (Pym, 2011, p. 5). ${ }^{7}$ Also crowd-sourcing becomes more and more popular. On Facebook, the users are encouraged to vote on the best Google Translator translations of the posts in foreign languages or to propose their own translations in order to develop the translation engine further. Google also offers to its users Google Translator Kit, which is a set of CAT tools that can be used for free in exchange for the 'donation' of the performed translation to Google (Pym, 2011, p. 5-6).

As a result, the control of the market shifts from the persons specializing in translation to the persons fluent with information technology. It appears that only very few translational fields are still not affected by this trend, e.g. literary translation (Pym, 2011, p. 5). It results from the nature of literary translation, characterised by linguistic richness, metaphoricity, and strong cultural and social colouring. It is due to these traits that literary texts should not be translated with the use of CAT programs. Therefore, it should not be surprising that translators, who lose commissions as well as money and prestige, fight with the overabundance of technology in the process of translation. Translators discredit the automatic translation in any possible way. An interesting example is the Canadian translator's association OTTIAQ (Ordre des traducteurs, terminologu es et interprétes agréés $d u$ Québec) that regularly publishes messages to anyone concerned. In some of them, one can find statements such as "the automatic translator applications now available to the general public may seem useful (...). But text generated by such software can in no way be considered as the equivalent of a true translation, which means it should be revised by a professional translator" (Pym, 2011, p. 5; italics in Pym).

The behaviour of interpreters appears to be even more interesting as they seem to be caught between the devil and the deep blue sea. On the one hand, an interpreter who works on professional equipment, e.g. cabins for simultaneous translation, earns more per hour than an interpreter working without such support. On the other hand, the development of technology made it possible to interpret from home, and as a result, the competition on the labour market intensifies. Hence, trying to protect their labour fields and opposing the latest technologies, interpreters claim that a proper translation is possible only on

7 At the same time, literary translations remain one of the worst paid types of translation. 
professional equipment and on the spot, so that a translator could feel the atmosphere and see every gesture and mimics of the speaker (Pym, 2011, p. 4).

\section{CONCLUSION}

To sum up, CAT combines in one program numerous useful or even necessary tools and hence it surely facilitates the work of translators who deal with texts that are standard, predictable and characterized by an intensive use of terminology. However, they are not particularly useful to literary translators, who work on texts that are rich linguistically, culturally and socially; they might rather lead to the decrease of the translation quality.

Perhaps it is not an invalid fact that the first users of CAT programs were translators of technical texts as they were one of few that could handle the first "raw" versions of CAT. They also commonly translated various software and hence computer files of different formats, which were not supported by standard office programs. In the end, technical translators were the ones who developed CAT programs and CATs were developed mostly for them. It is not an accident that the first publications on the use of technology in translation are written by a technical translator, Bert Esselink - A Practical Guide to Software Localization and A Practical Guide to Localization (Folaron, 2010, p. 431).

Finally, it is worth highlighting that even though this short article focuses on computer technology, more and more attention is given to the translation applications that could be used by tablets and smartphones, e.g. OneSky app. Perhaps, in the near future, a translator will be able to work on a text always and everywhere/anywhere. These changes call for one more concern, namely translator's education. All new technologies should be an integral part of any translation course or studies as they are no longer just a titbit. Their use has become a very basic translation skill and it is no longer an advantage but an absolute necessity for anyone wishing to work as a translator.

\section{REFERENCES}

1. Baker, M. (2014). The Changing Landscape of Translation and Interpreting Studies. In: S. Bermann, \& C. Porter (Eds.), A Companion to Translation Studies (pp.15-27). Oxford: John Wiley \& Sons.

2. Choudhury, R., \& McConnell, B. (2013). Translation Technology Landscape Report. TAUS Translation Automation User Society. Retrieved January 2017, from https://pl.scribd.com/ document/134651594/TAUS-Translation-Technology-Landscape-Report.

3. DGT-Translation Memory. Retrieved January 2017, from https://ec.europa.eu/jrc/en/ language-technologies/dgt-translation-memory.

4. Folaron, D. A. (2010). Translation tools. In: Y. Gambier, \& L. van Doorslaer (Eds.), Handbook of Translation Studies. (pp. 429-436). Vol. 1. Amsterdam: John Benjamins Publishing Company.

5. Hejwowski, K. (2007). Kognitywno-komunikatywna teoria przekładu [Translation. A CognitiveCommunicative Approach]. Warszawa: Wydawnictwo Naukowe PWN.

6. Kielar, B. Z. (1988). Tłumaczenie i koncepcje translatoryczne [Translation and translational concepts]. Wrocław: Zakład Narodowy Imienia Ossolińskich. 
7. Littau, K. (2011). First steps towards a media history of translation. Translation Studies 4(3), 261-281. DOI: 10.1080/14781700.2011.589651.

8. Products for standalone use. Retrieved December 2016 from https://www.memoq.com/en/ translation-products/versions-and-pricing/version-comparison/individual-use.

9. Munday, J. (2004). Introducing translation studies: Theories and applications. London: Routledge.

10. Software comparison tool. Retrieved December 2016 from http://www.proz.com/softwarecomparison-tool/cat/cat_tools/2 ED.

11. Pym, A. (2011). What technology does to translating? The International Journal for Translation E Interpreting Research, 3(1), 1-10.

12. Wei,H. (2013). Investigating Core Technologies in Computer-aided Multilingual Translation Memory. RetrievedJanuary2017fromatlantis-press.com\%2Fphp\%2Fdownload_paper.php\%3Fid\%3D7 452\&usg=AFQjCNHZrAN8yXF6T-Hm_hgpafeG_glIpQ\&sig2=rcROAYPjlPGFt_S7VrEY7A.

13. Wojtasiewicz, O. (2007). Wstęp do teorii ttumaczenia [An introduction to the translation theory]. Warszawa: Wydawnictwo Albatros. 